\title{
Effect of Fuselage Cross Section on Aerodynamic Characteristics of Reusable Launch Vehicles
}

\author{
Kenji Tadakuma', Yasuhiro Tani' ${ }^{2}$, Shigeru Aso ${ }^{2}$ \\ ${ }^{1}$ Innovative R \& D Engineering Company, Toyota Motor Corporation, Toyota, Japan \\ ${ }^{2}$ Department of Aeronautics and Astronautics, Kyushu University, Fukuoka, Japan \\ Email: s21490414@nucba.ac.jp
}

How to cite this paper: Tadakuma, K., Tani, Y. and Aso, S. (2016) Effect of Fuselage Cross Section on Aerodynamic Characteristics of Reusable Launch Vehicles. Open Journal of Fluid Dynamics, 6, 222233.

http://dx.doi.org/10.4236/ojfd.2016.63017

Received: August 27, 2016

Accepted: September 17, 2016

Published: September 20, 2016

Copyright $\odot 2016$ by authors and Scientific Research Publishing Inc. This work is licensed under the Creative Commons Attribution International License (CC BY 4.0).

http://creativecommons.org/licenses/by/4.0/

\begin{abstract}
An experimental study on examining aerodynamic characteristics of fuselage cross sections for RLVs (Reusable Launch Vehicles) was conducted at Mach number 0.3, 0.9 and 4.0 in the wind tunnel of ISAS (Institute of Space and Astronautical Science), JAXA (Japan Aerospace Exploration Agency). Three bodies, having the same projected area and length, with and without a set of fins, were tested. Their cross sections are a circle, a square and a triangle with rounded corners. The results showed that the fuselage cross sections had large effects on aerodynamic characteristics in subsonic and transonic flow. The lift coefficient of the model having the triangular cross section with a set of the fins was larger than that of the others in high angles of attack region due to contributions of the separation vortices generated from the fuselage expanding to the wing surface.
\end{abstract}

\section{Keywords}

Reusable Launch Vehicle, Aerodynamic Characteristics, Fuselage Cross Section, Separation Vortex

\section{Introduction}

Space transportation system is one of the most important infrastructures for space activities. Low cost, improvement of reliability and safety are required for the development of RLV (Reusable Launch Vehicle). To achieve high aerodynamic performance in the whole flight speed region is one of the most important issues in the development of RLV. High lift performance at low speed regime makes possible a shorter landing distance, and high lift-to-drag ratio performance allows easy approach during landing process, larger down and cross range in high speed region.

Such RLVs have larger aerodynamic effects on a fuselage configuration due to a larg- 
er fuselage cross section compared with that of aircrafts. Therefore, investigating a favorable fuselage configuration of the RLVs is important to enhance the aerodynamic performances.

Examples of past studies [1]-[8] related to aerodynamic characteristics due to the fuselage configuration include missiles which studied effect on the location of vortex breakdown on the delta wing. While many useful studies have been carried out, very few studies have empirically investigated the aerodynamic effects on the fuselage cross sections for RLVs from low speed to supersonic region, including the changes of angle of attack.

Therefore, the purpose of this study is to identify aerodynamic effects due to different fuselage configurations to enhance aerodynamic performance for RLV. In this paper, we report experimental results by using three fuselage cross sections, such as a circle, a triangle and a square, having that same projected area and length, with and without a set of fins at $M_{\infty}=0.3,0.9$ and 4.0.

\section{Experimental Apparatus and Procedures}

\subsection{Wind Tunnel}

The experiments were carried out in the transonic wind tunnel, supersonic wind tunnels of ISAS, JAXA and in the low speed wind tunnel of Kyushu University. Both the transonic and supersonic tunnels are blow-down type facility. Each operating Mach numbers is from 0.3 to 1.3 and from 1.3 to 4.0 , respectively. The size of test section is $600 \mathrm{~mm}$ width, $600 \mathrm{~mm}$ height. The low speed wind tunnel of Kyushu University has a closed circuit and an open test section which diameter of nozzle exit is 2,000 $\mathrm{mm}$. The max speed is $21 \mathrm{~m} / \mathrm{s}$.

\subsection{Model and Instruments}

Figure 1 and Figure 2 show the geometry and photograph of the models. The "Circle" means the fuselage-alone model with the circular fuselage cross section, the "Square" means the fuselage-alone model with square one and the "Triangle" means fuselage-alone model with triangular one. These three fuselage-alone models are called "Fuselage models" in the present study. The "Fuselage models" have a same projected area, $0.0194 \mathrm{~m}^{2}$ and a same length, $0.3448 \mathrm{~m}$. As shown in Figure 1, the fuselage cross section smoothly varies from a triangle or a square to a circle toward the front nose of the model. The nose tip of these models has a same radius of $7 \mathrm{~mm}$. Each corner of the "Fuselage models" has a same radius of $6 \mathrm{~mm}$ which is one tenth of the body span.

Figure 2 shows the "Square with wings" that means wing-body configuration with triangular fuselage cross section, "Triangle with wings" also means wing-body configuration with triangular one. These two models of the wing-body configuration are called "Wing-body models" in the present study. The projected area of each "Wing-body model" has a same area, $0.0314 \mathrm{~m}^{2}$, used as a reference area. The wings of these models have a delta planform of modified NACA0010 cross section with 45 degree sweepback angle, referred to past studies [9]-[13] on RLVs, and are demountable from the body. 

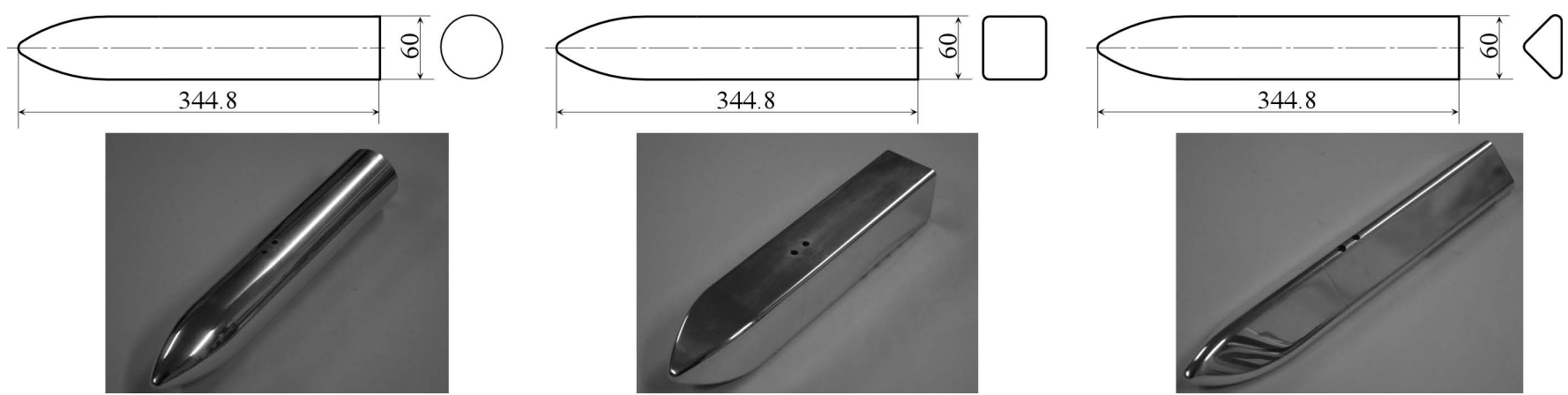

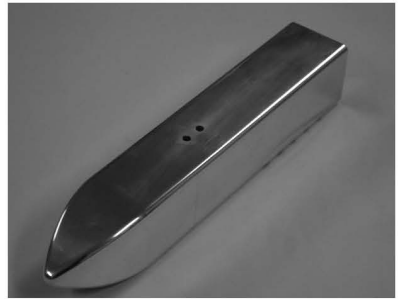

(b) Square

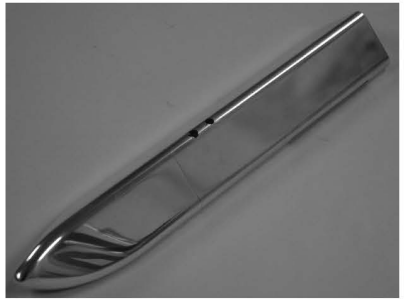

(c) Triangle

Figure 1. Geometry and photograph of fuselage-alone models.
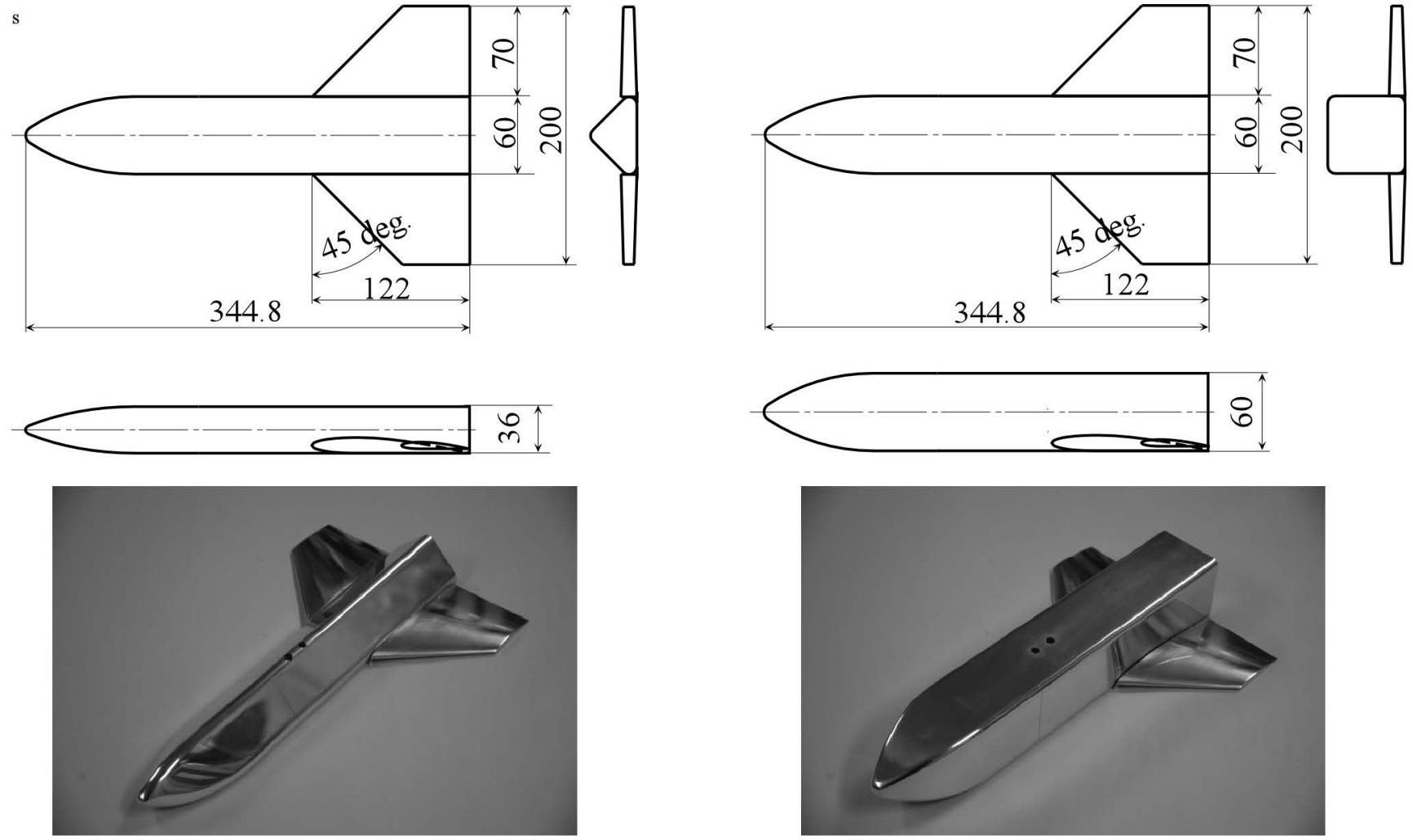

(a) Triangle with wings

(b) Square with wings

Figure 2. Geometry and photograph of wing-body models.

The full length is $0.3448 \mathrm{~m}$, used as a reference length. Center of the balance in all models is located at $231 \mathrm{~mm}$ behind from the front nose edge of the models. A sting-type six-component internal balance was used for the measurement of forces and moments.

\subsection{Test Conditions}

Table 1 shows test conditions. The transonic and supersonic wind tunnels were used to obtain aerodynamic characteristics and oil flow visualization results. The experiments were conducted at Mach number 0.3, 0.9 and 4.0 in the angle of attack $\alpha$ varying 
Table 1. Test conditions for measurement of aerodynamic forces and moments in the transonic and supersonic wind tunnel.

\begin{tabular}{lccc}
\hline$M_{\infty}$ & Model & $\alpha(\mathrm{deg})$. & $R e$ \\
\hline 0.3 & Circle & $-15 \sim 40$ & $3.1 \times 10^{6}$ \\
0.3 & Square & $-15 \sim 40$ & $3.1 \times 10^{6}$ \\
0.3 & Triangle & $-15 \sim 40$ & $3.1 \times 10^{6}$ \\
0.3 & Square with wings & $-15 \sim 40$ & $3.1 \times 10^{6}$ \\
0.3 & Triangle with wings & $-15 \sim 40$ & $3.1 \times 10^{6}$ \\
0.9 & Circle & $-15 \sim 40$ & $7.3 \times 10^{6}$ \\
0.9 & Square & $-15 \sim 40$ & $7.3 \times 10^{6}$ \\
0.9 & Triangle & $-15 \sim 40$ & $7.3 \times 10^{6}$ \\
0.9 & Square with wings & $-15 \sim 35$ & $7.4 \times 10^{6}$ \\
0.9 & Triangle with wings & $-15 \sim 32.5$ & $7.3 \times 10^{6}$ \\
4.0 & Square with wings & $-15 \sim 40$ & $8.2 \times 10^{6}$ \\
4.0 & Triangle with wings & $-15 \sim 40$ & $8.2 \times 10^{6}$ \\
\hline
\end{tabular}

from 0 degree to 40 degrees, except for the case of the "Wing-body models" at Mach number 0.9 that have possibilities of excessive loads over the balance capability. The flow visualization of smoke-wire method was conducted in the low speed wind tunnel of Kyushu University to understand the flow field around the models.

\section{Results and Discussion}

\subsection{Aerodynamic Characteristics}

Figures 3-5 show the results of aerodynamic coefficients at Mach number 0.3, 0.9 and 4.0. Here, the lift coefficient, drag coefficient and pitching moment coefficient are dimensionless number. These coefficients are defined by Equation (1) to Equation (3).

$$
\begin{aligned}
& \text { Lift coefficient }=F_{z} /\left(A \cdot q_{\infty}\right) \\
& \text { Drag coefficient }=F_{x} /\left(A \cdot q_{\infty}\right) \\
& \text { Pitching moment coefficient }=M_{y} /\left(A \cdot q_{\infty} \cdot L\right)
\end{aligned}
$$

Here, $F_{z}$ is lift force, $F_{x}$ is drag force, $M_{y}$ is pitching moment, $A$ is frontal projected area, $q_{\infty}$ is dynamic pressure of main flow, $L$ is model length. Note, the projected area of the "Wing-body models" was used as a reference area for the calculation of all aerodynamic characteristics to compare with all models in the same graphs although the area of the "Fuselage models" differs from that of the "Wing-body models". Positive value of the pitching moment coefficient indicates a nose-up moment. The reference center of the moment locates front end of the nose part.

From Figure 3(a), as for the "Fuselage models", the "Triangle" case is achieved larger lift coefficient when the angle of attack is over about 20 degrees, compared to the other "Fuselage models". As for the "Wing-body models", both cases of the "Square with fins" and "Triangle with fins" are almost same lift coefficient independent of the 


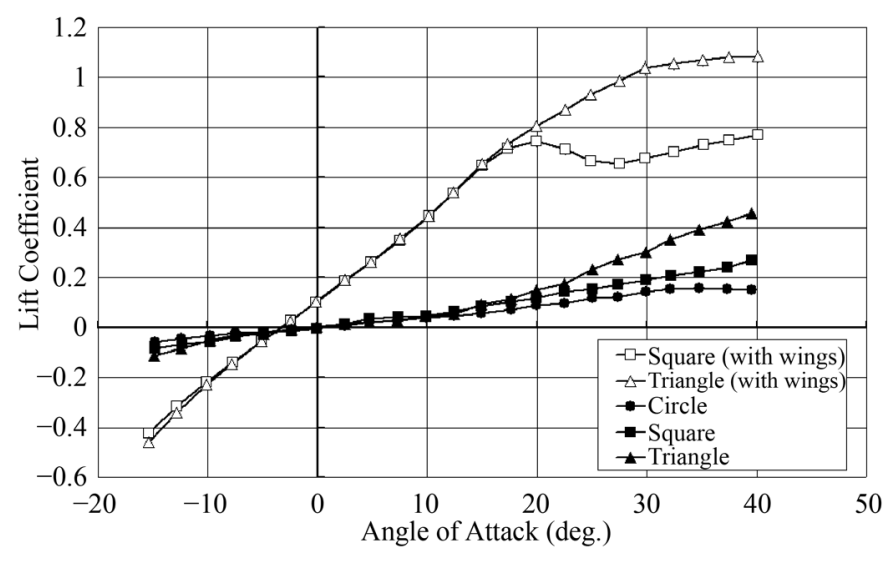

(a)

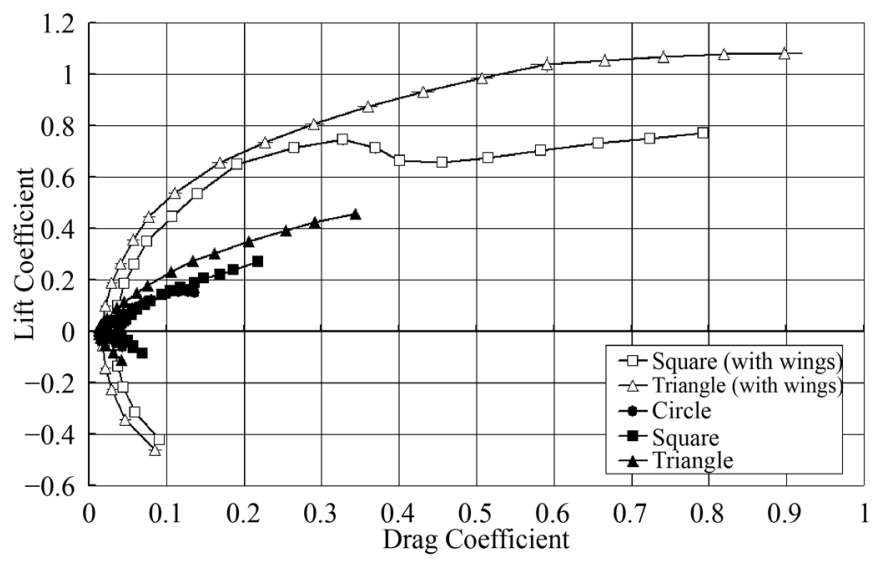

(c)

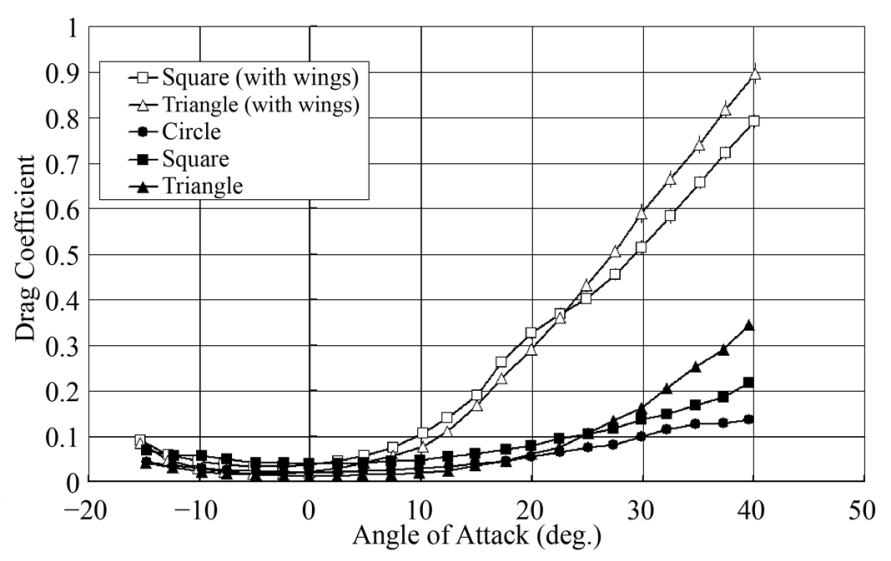

(b)

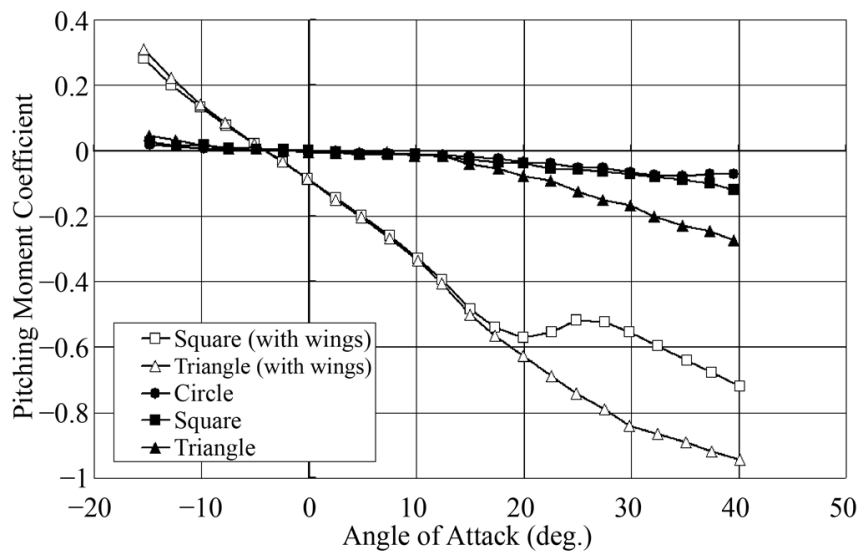

(d)

Figure 3. Aerodynamic characteristics of $M_{\infty}=0.3$. (a) Lift coefficient; (b) Drag coefficient; (c) Polar curve; (d) Pitching moment coefficient.

cross-sectional shape when the angle of attack is within 17.5 degrees, but those are obviously different as the angle of attack goes over 20 degrees. The "Square with wings" stalls obviously. On the other hand, the "Triangle with wings" does not show such the specific stalling as shown in the case of the "Square with wings", and is obtained much larger lift coefficient compared with the "Square with wings" case. In addition, the difference of the lift coefficient between the "Triangle with wings" and the "Square with wings" in high angle of attack region is larger than the difference between the fuselage-alone models of "Triangle" and "Square". This result indicates that the combination of the triangular cross-sectional fuselage and delta wings has a synergy aerodynamic effect which increases lift coefficient effectively.

From Figure 3(b), as for the "Fuselage models", the "Triangle" case indicates larger drag coefficient when the angle of attack is over about 20 degrees, compared with that of the other "Fuselage models", because the lift increase induces larger drag. In low angle-of-attack region, the drag coefficients of the "Fuselage models" are arranged in order of "Triangle", "Square" and "Circle", because of the difference of the cross sectional area against the main flow. As for the "Wing-body models", the tendency of the drag 
coefficient is almost same as the "Fuselage models".

Figure 3(c) shows polar curve. The "Triangle with wings" case is larger than that of the "Square with wings" when the drag coefficient is over about 0.3 which can be considered from the result of the drag and lift coefficient.

Figure 3(d) shows pitching moment coefficients, which are correspond to lift and drag coefficient results. From the results, the center-of-pressure location of the "Square with wings", when the angle of attack is over 20 degrees, is moved forward because the vortex on the wing can be considered breakdown.

Figure 4 shows the aerodynamic characteristics at Mach number 0.9. Figures 4(a)4(d) show lift coefficient, drag coefficient, polar curve and pitching moment coefficient, respectively. The qualitative tendency is almost same as that of Mach number 0.3 although quantitative difference. The difference of the lift coefficient between "Square with wings" and "Triangle with wings" in high angle-of-attack region are smaller than that of Mach number 0.3 case. This is probably because Mach and Reynolds number effects result in decrease of the separation-vortex effects on the fuselage and delta wings [14]-[16].

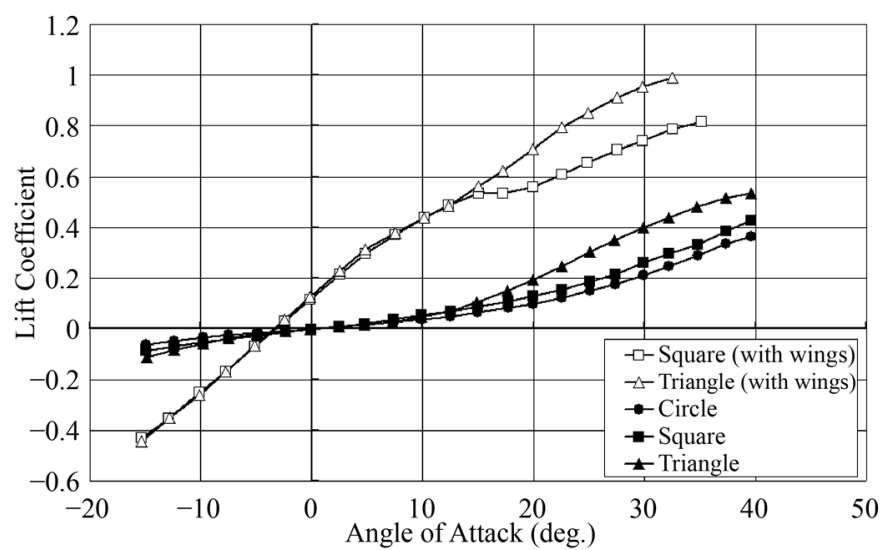

(a)

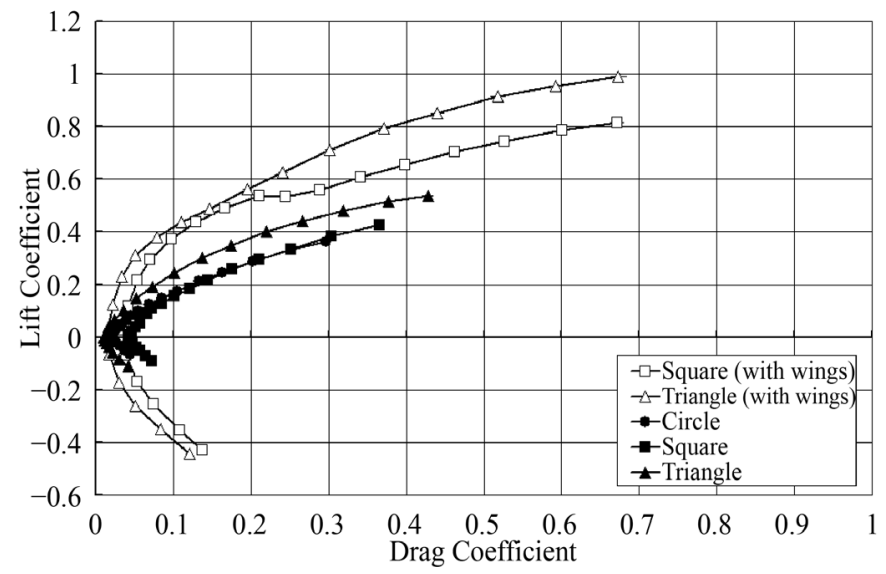

(c)

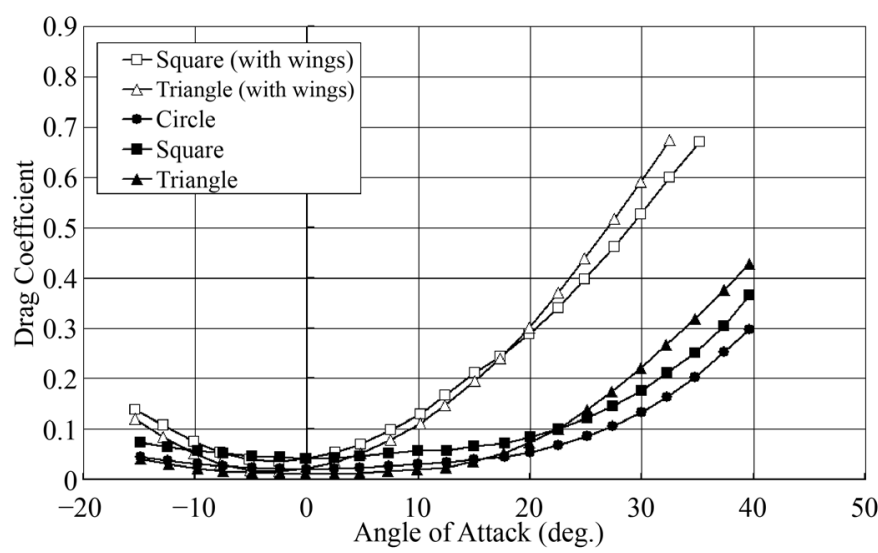

(b)

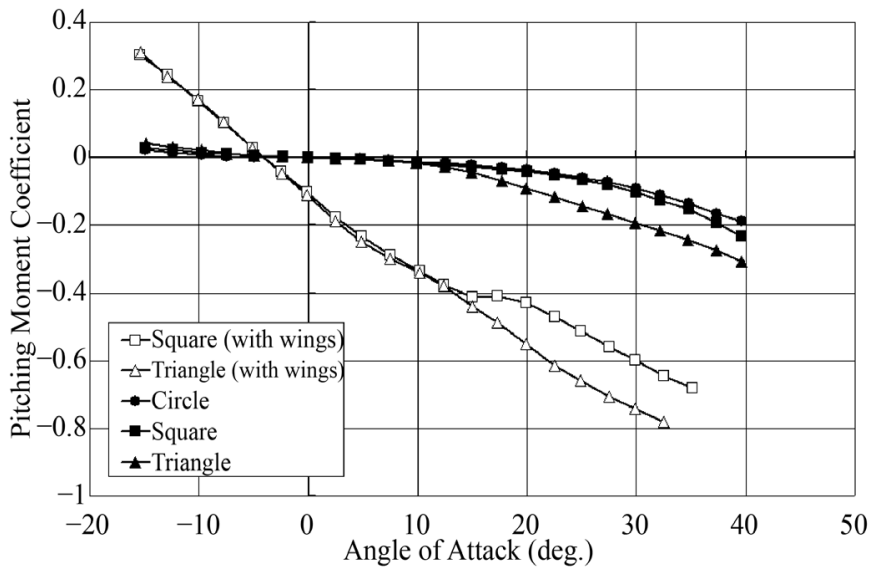

(d)

Figure 4. Aerodynamic characteristics of $M_{\infty}=0.9$. (a) Lift coefficient; (b) Drag coefficient; (c) Polar curve; (d) Pitching moment coefficient. 
Figure 5 shows the aerodynamic characteristics at Mach number 4.0. Figures 5(a)-5(d) show lift coefficient, drag coefficient, polar curve and pitching moment coefficient, respectively. The qualitative tendency at Mach number 4.0 differs from the results of the Mach number 0.3 and 0.9 , significantly. The aerodynamic characteristics at Mach number 4.0 are almost determined by the projected area only, which is caused by compressibility effect due to the shock waves [16]. Both "Wing-body models" have same projected area, which results in almost same aerodynamic characteristics, being approximately calculable by Newtonian theory [16]. It is presumed that the effect of separation vortex to the body decreases due to Mach number and Reynolds number effects and low back pressure getting closer to vacuum behind the body as the Mach number increases, in contrast to the region of low Mach number flow. Note, the "Fuselage models" experiments at Mach number 4.0 were not conducted because the results had been expected the same tendency as the "Wind-body models".

\subsection{Flow Visualization}

The flow visualization was conducted by oil flow and smoke wire method to discuss the flow fields. Figure 6 and Figure 7 show comparison of the flow fields between the

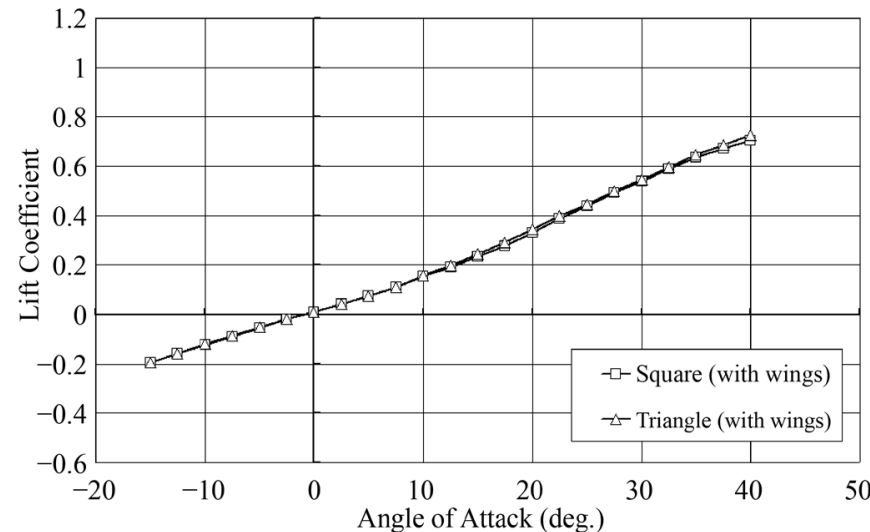

(a)

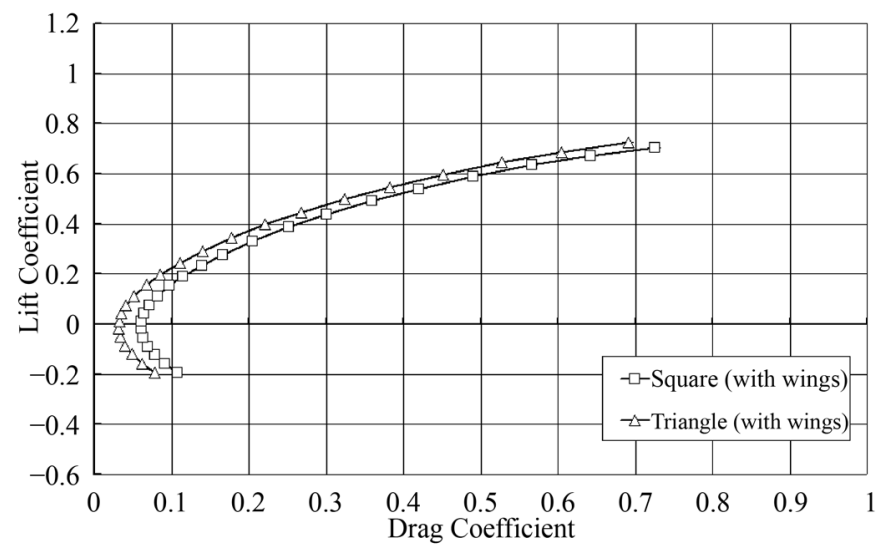

(c)

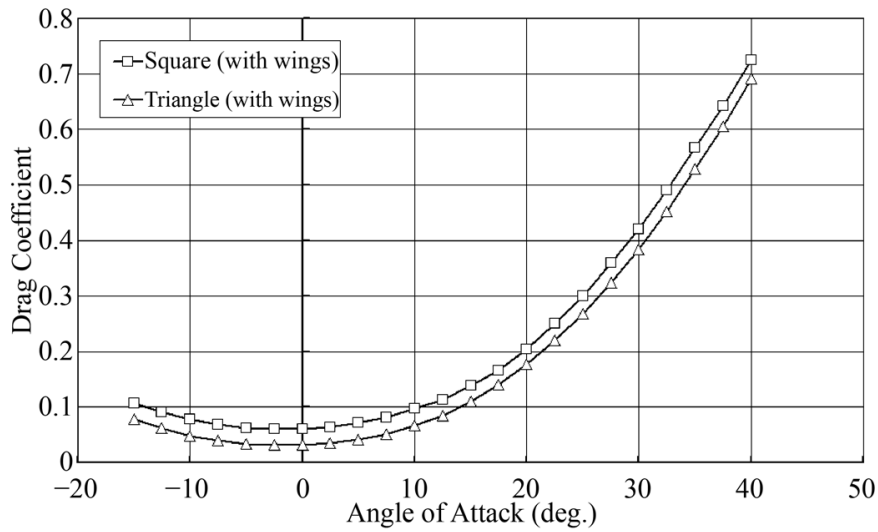

(b)

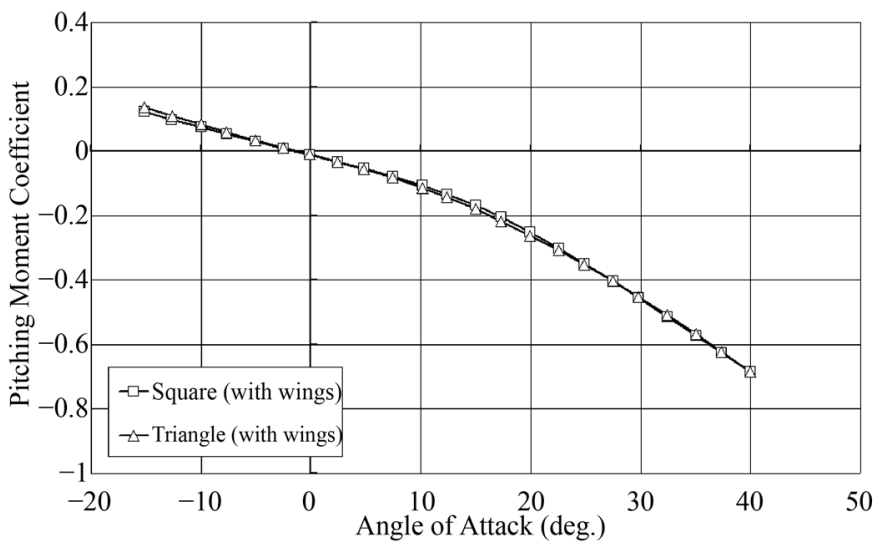

(d)

Figure 5. Aerodynamic characteristics of $M_{\infty}=4.0$. (a) Lift coefficient; (b) Drag coefficient; (c) Polar curve; (d) Pitching moment coefficient. 
Primary

separation line

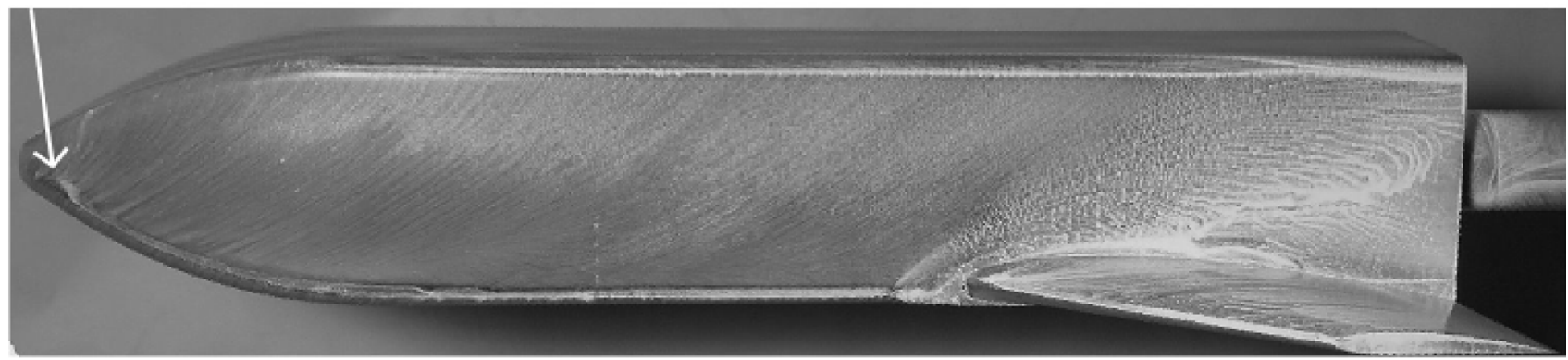

Primary

(a) Square with wings

separation line

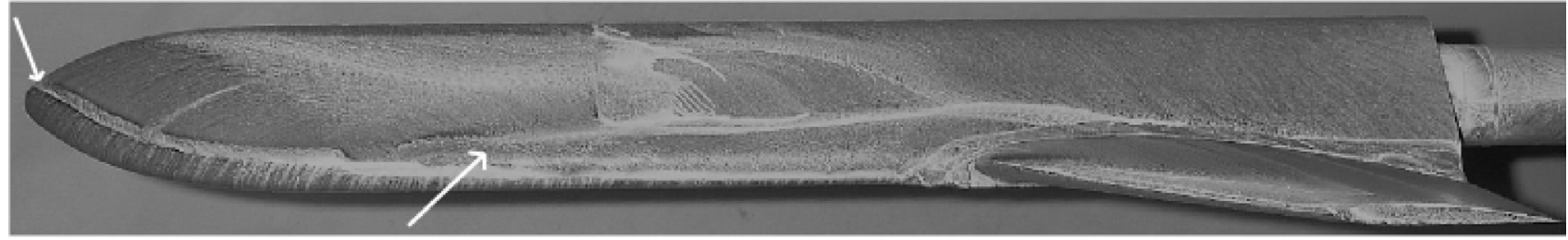

Secondary

separation line

(b) Triangle with wings

Figure 6. Oil flow visualization results of "Square with wings" and "Triangle with wings" at $\alpha=30 \mathrm{deg}$. and $M_{\infty}=0.3$ (side view).

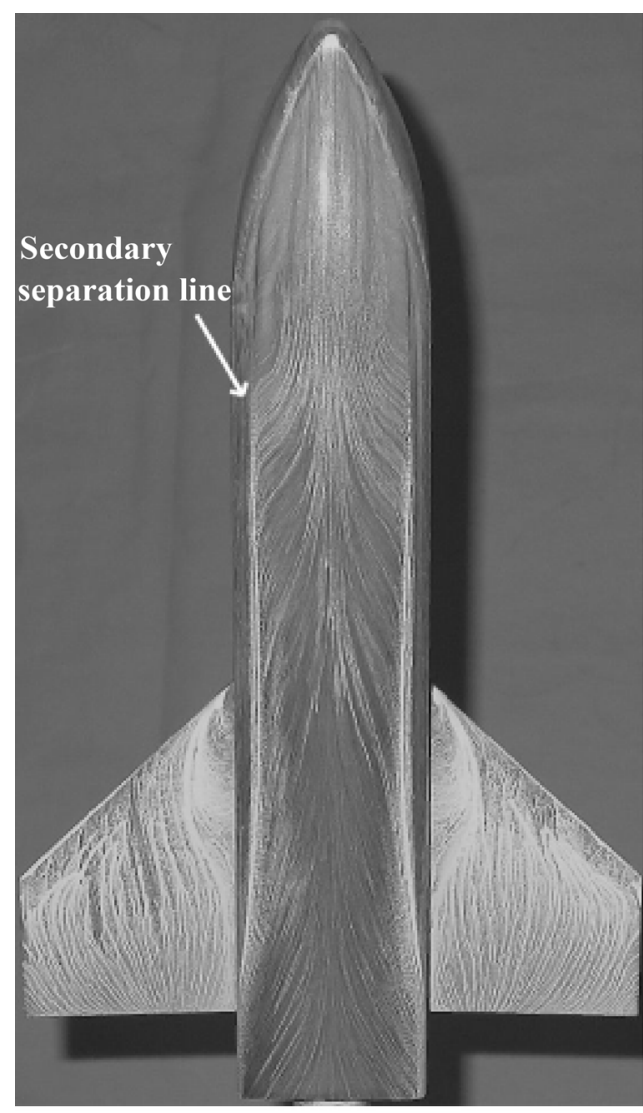

(a) Square with wings

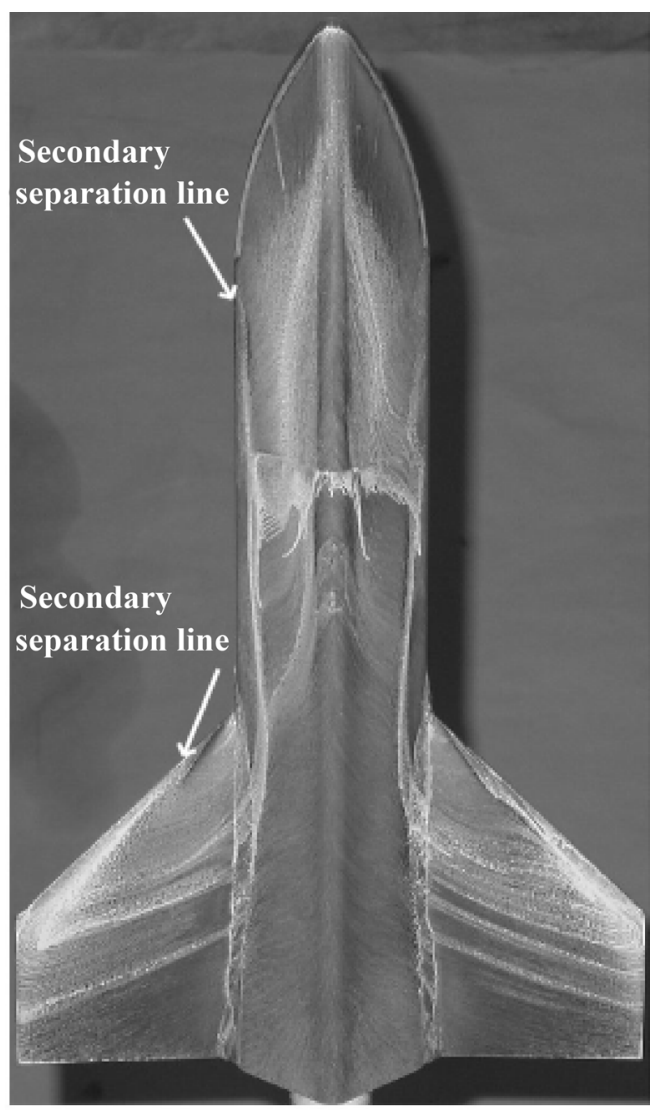

(b) Triangle with wings

Figure 7. Oil flow visualization results of "Square with wings" and "Triangle with wings" at $\alpha=30$ deg. and $M_{\infty}=0.3$ (top view). 
"Wing-body models" at angle of attack of 30 degrees, which showed a significant difference of the lift coefficient between the models.

Figure 6 shows side view of the oil flow visualizations. From Figure 6, the primary separation line indicated by arrows shows flow separation of primary vortex from lower part of the side around the nose. For the "Square with wings" in Figure 6(a), secondary separation line cannot be found on the lateral surface of the fuselage, while the secondary separation line in the Figure 6(b) of the "Triangle with wings" is identifiable. This flow pattern of the "Square with wings" in Figure 6(b) showed the primary separation vortex did not be reattached on the side of the fuselage.

Figure 7 shows top view of the oil flow visualizations. From Figure 7, the both models have secondary separation lines on the upper part of the fuselage. For the "Square with wings" in Figure 7(a), the secondary separation line can be seen from about $30 \%$-model-length location and it continues to the rear end of the model. The thick oil streak is observed on the wings, which can be considered the flow on the wing states "flow separation".

For the "Triangle with wings" in Figure $7(\mathrm{~b})$, the secondary separation line on the fuselage is observed, that is same line as observed in the side view in Figure 6(b). The streamlines on the wings are formed toward the wing tip from the top of the triangle fuselage, which flow pattern showed the separation vortex on the fuselage was expanded to the flow on the wing.

Figure 8 and Figure 9 show flow visualization results by smoke-wire method to compare with the flow fields of the "Wing-body models" spatially, at same angle of attack as the oil flow visualization [17]. The smoke was shined by light through slit from the side, then the spatial flow fields of cross sectional planes of $x / L=0.75$ and $x / L=1$ were photographed from the down-stream position. Here, $x$ is a distance from front edge, $L$ is model length.

In Figure 8(a), the separation vortex of the "Square" model is formed above the fuselage, and then the size of the vortex is grown larger as the vortex moves downstream. From the Figure 8(b), the model of the "Square with wings" forms almost same separation vortex as the fuselage-alone model, while it is observed vague smoke vortex on the wing in the model-end plane. Considering the flow fields including the oil flow visualization result of Figure 6 and Figure 7, the flow on and above the wing shows "flow separation".

In Figure 9, the separation vortex on the fuselage of the both models is formed, and the size of the vortex is grown larger as the vortex moves downstream as same as Figure 8(a). However, the vortex formation of $x / L=1$ in Figure 9(b) differs from the "Square with wings" in Figure 8(b). The separation vortex generated from the fuselage is expanded to the wing in span-wise direction due to the shape of the fuselage, and then the vortex is larger than that of the "Square with wings".

From these visualization results, the larger lift coefficient of the "Triangle with wings" compared with that of the "Square with wings" results from expanding the influence area of the separation vortex generated from the fuselage to the wing in the case 


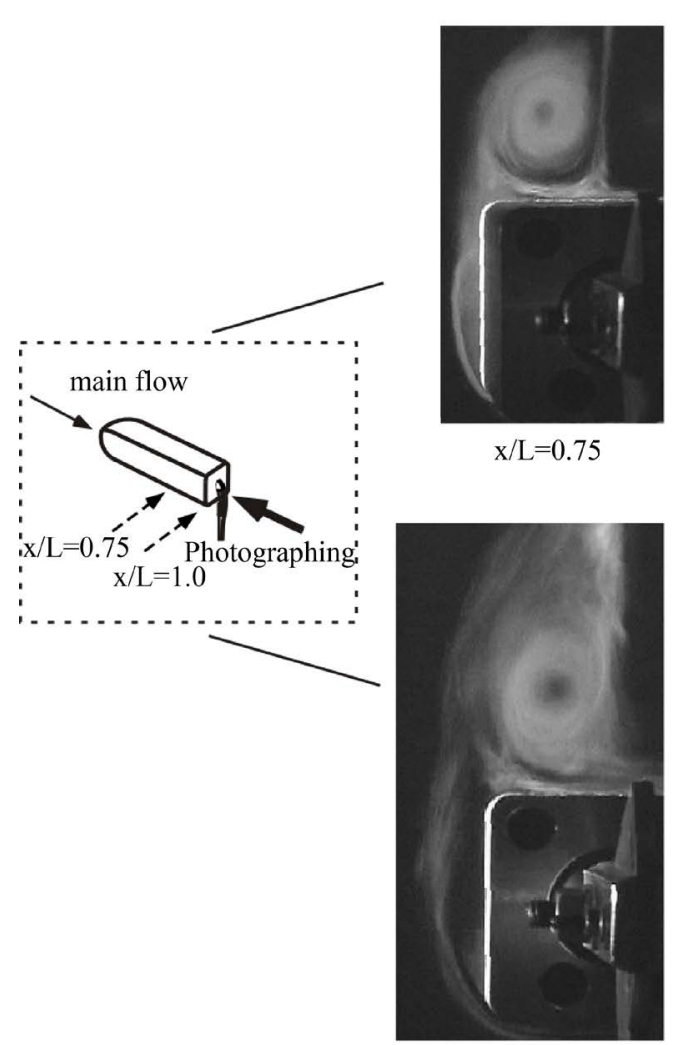

$x / L=1.0$

(a) Square

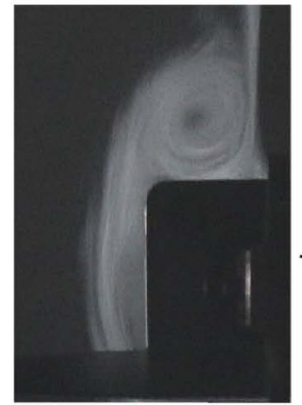

$\mathrm{x} / \mathrm{L}=0.75$

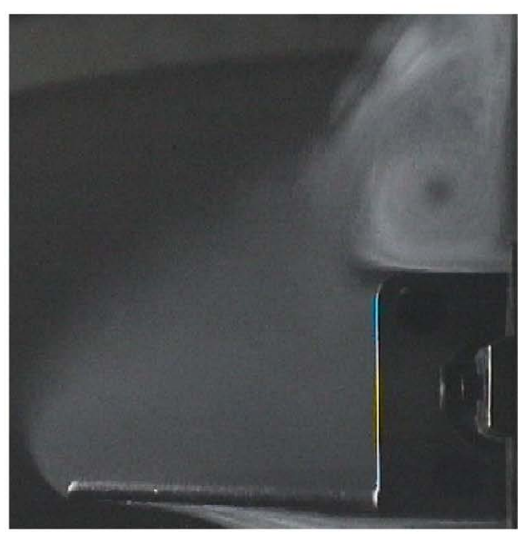

$x / L=1.0$

(b) Square with wings

Figure 8. Smoke wire visualization result of "Square" and "Square with wings" at $\alpha=30$ deg., $U_{\infty}=3 \mathrm{~m} / \mathrm{s}$.

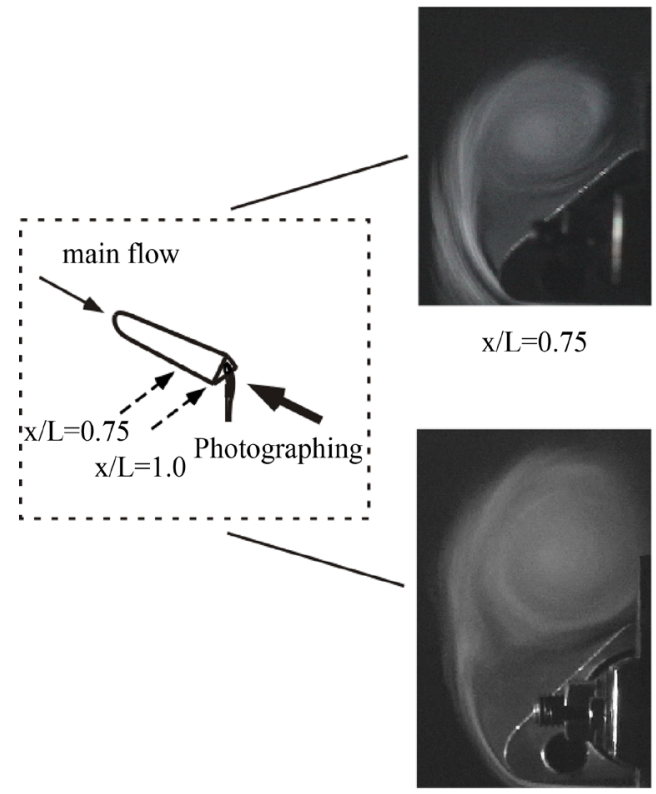

$\mathrm{x} / \mathrm{L}=1.0$

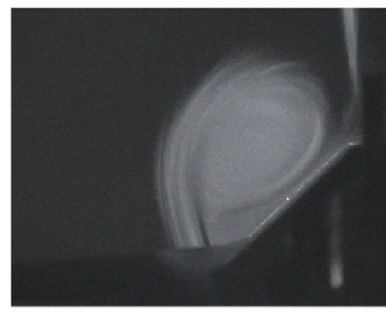

$\mathrm{x} / \mathrm{L}=0.75$

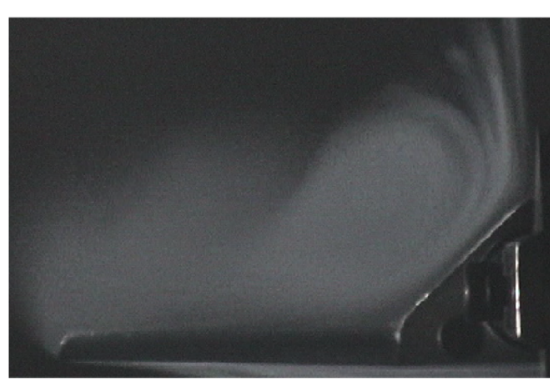

$\mathrm{x} / \mathrm{L}=1.0$
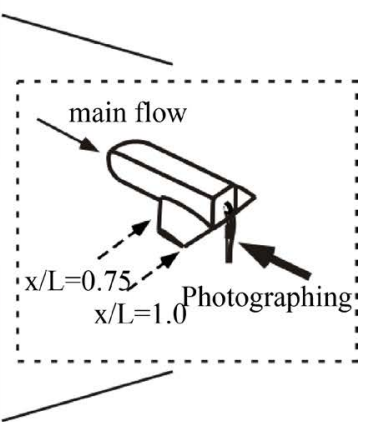

\section{(a) Triangle}

(b) Triangle with wings

Figure 9. Smoke wire visualization result of "Triangle" and "Triangle with wings" at $\alpha=30$ deg., $U_{\infty}=3 \mathrm{~m} / \mathrm{s}$ [17]. 
of "Triangle with wings". In addition, the flow on the wing in the case of the "Square with wings" is separated.

In other word, it is presumed that the synergy effect of "Triangle with wings" which increases lift coefficient effectively referred to past studies [6] [7]. Ericsson et al. has reported wing-body configurations moved the location of the separation vortex breakdown to upstream on the delta wing and decreased the breakdown angle of attack compared with fuselage-alone model [6] [7]. In addition, from the report of Matsuno [13], the lift coefficient of the 45-degree-sweep delta wing is the same as the wings in the present study stalled at the angle of attack of around 25 degrees. The "Square with wings" model of the present study indicated smaller stall angle of attack than that of the 45-degree-sweep delta wing. This is because the separation vortex breakdown occurs earlier due to the effect of the fuselage, as same as the results of Ericsson et al. On the other hand, the lift coefficient of the "Triangle with wings" of the present study does not show the stall over angle of attack of 30 degrees because the influence area of the fuselage separation vortex expands to the wing.

\section{Conclusions}

An experimental study on examining aerodynamic characteristics of fuselage cross sections for RLVs was conducted at Mach number 0.3, 0.9 and 4.0 in the wind tunnel of ISAS, JAXA. This study revealed that the fuselage cross sections had large effects on aerodynamic characteristics in subsonic and transonic flow. The lift coefficient of the model having the triangular cross section with a set of fins was larger than that of the square model with a set of fins in high angles of attack region due to contributions of the separation vortices generated from the fuselage expanding to the wing surface. However, the qualitative tendency of the aerodynamic characteristics at Mach number 4.0 in supersonic region differed from the results in the subsonic and transonic region significantly. The aerodynamic characteristics at Mach number 4.0 were determined by the projected area only, which was caused by Mach number and Reynolds number effects.

\section{Acknowledgements}

Thanks to the following:

- Open Journal of Fluid Dynamics for publishing this paper;

- ISAS (Institute of Space and Astronautical Science) in JAXA (Japan Aerospace Exploration Agency) agreed with utilization of wind tunnel facilities;

- Wataru Morita, graduated student at the time in Kyushu University, helped us to gather the aerodynamic data.

\section{References}

[1] Daniel, D.C., Yechout, T.R. and Zollars, G.J. (1982) Experimental Aerodynamic Characteristics of Missiles with Square Cross Sections. Journal of Spacecraft and Rockets, 19, 167-172. http://dx.doi.org/10.2514/3.62228 
[2] Sigal, A. and Lapidot, E. (1989) Aerodynamic Characteristics of Configurations Having Bodies with Square, Rectangular, and Circular Cross Sections. Journal of Spacecraft and Rockets, 26, 85-89. http://dx.doi.org/10.2514/3.26036

[3] Sigal, A. (1995) Aerodynamic Characteristics of Rectangular Cross Sectional Bodies at $M_{\infty}$ $=0.85$. Journal of Aircraft, 25, 1018-1022. http://dx.doi.org/10.2514/3.45697

[4] Nelson, H.F. (1989) Wing-Body Interference Lift for Supersonic Missiles with Elliptical Cross-Section Fuselages. Journal of Spacecraft and Rockets, 26, 322-329. http://dx.doi.org/10.2514/3.26075

[5] Est, B.E. and Nelson, H.F. (1992) Aerodynamic Forces on Noncircular Cross-Section Missile Forebodies. Journal of Aircraft, 29, 612-618. http://dx.doi.org/10.2514/3.46209

[6] Ericsson, L.E. (1998) Effect of Fuselage Geometry on Delta-Wing Vortex Breakdown. Journal of Aircraft, 35, 898-904. http://dx.doi.org/10.2514/2.2410

[7] Straka, W.A. and Hemsch, M.J. (1994) Effect of Fuselage on Delta Wing Vortex Breakdown. Journal of Aircraft, 31, 1002-1005. http://dx.doi.org/10.2514/3.46600

[8] Hall, R.M. (1987) Influence of Forebody Cross-Sectional Shape on Wing Vortex-Burst Location. Journal of Aircraft, 24, 645-652. http://dx.doi.org/10.2514/3.45490

[9] Sippel, M., Klevanski, J., Burkhardt, H., Eggers, T., Bozic, O., Langholf, P. and Rittweger, A. (2002) Progress in the Design of a Reusable Launch Vehicle Stage. AIAA Paper, AIAA2002-5220.

[10] Spies, J. (2002) RLV Hopper Consolidated System Concept. IAC-02-V.4.02.

[11] Wallace, J., Olds, J., Charania, A.C. and Woodcock, G. (2003) A Study of Arts: A Dual-Fuel Reusable Launch Vehicle with Launch Assist. AIAA Paper, AIAA-2003-5269. http://dx.doi.org/10.2514/6.2003-5269

[12] Brown, F.N. and Olds, R.J. (2005) Evaluation of Multidisciplinary Optimization (MDO) Techniques Applied to a Reusable Launch Vehicle. AIAA Paper, AIAA-2005-707.

[13] Matsuno, T., Yokouchi, S. and Nakamura, Y. (2004) Small Leading-Edge Flap for Flow Control on a 45-Deg Delta Wing. Journal of the Japan Society for Aeronautical and Space Sciences, 52, 429-434. http://dx.doi.org/10.2322/jjsass.52.429

[14] Luckring, J.M. (2004) Compressibility and Leading-Edge Bluntness Effects for a 65 deg. Delta Wing. AIAA Paper, AIAA-2004-0765.

[15] Luckring, J. M. (2004), Reynolds Number, Compressibility, and Leading-Edge Bluntness on Delta-Wing Aerodynamics. $24^{\text {th }}$ International Congress of the Aeronautical Sciences.

[16] Kubota, H., Suzuki, K. and Watanuki, T. (2002) Aerothermodynamics of Space Vehicles. University of Tokyo Press, Tokyo.

[17] Tadakuma, K., Wataru, M., Tani, Y. and Aso, S. (2007) Effect of Fuselage Cross Sections on Aerodynamic Characteristics of Reusable Launch Vehicles in Subsonic Flow. Journal of the Japan Society for Aeronautical and Space Sciences, 55, 288-292.

http://dx.doi.org/10.2322/jjsass.55.288 
Submit or recommend next manuscript to SCIRP and we will provide best service for you:

Accepting pre-submission inquiries through Email, Facebook, LinkedIn, Twitter, etc. A wide selection of journals (inclusive of 9 subjects, more than 200 journals)

Providing 24-hour high-quality service

User-friendly online submission system

Fair and swift peer-review system

Efficient typesetting and proofreading procedure

Display of the result of downloads and visits, as well as the number of cited articles

Maximum dissemination of your research work

Submit your manuscript at: http://papersubmission.scirp.org/

Or contact ojfd@scirp.org 